\title{
The challenge of paediatric epilepsy nursing: An interview with Mrs. Jenny O'Brien, paediatric epilepsy nursing specialist at the Wirral University Teaching Hospital, UK
}

\author{
IOANNIS N. MAMMAS ${ }^{1-4}$ and DEMETRIOS A. SPANDIDOS ${ }^{1,3}$ \\ ${ }^{1}$ Institute of Paediatric Virology; ${ }^{2}$ Paediatric Clinic, Aliveri, 34500 Island of Euboea; \\ ${ }^{3}$ Laboratory of Clinical Virology, Medical School, University of Crete, 71003 Heraklion; \\ ${ }^{4}$ First Department of Paediatrics, University of Athens School of Medicine, 11527 Athens, Greece
}

Received July 31, 2020; Accepted October 24, 2020

DOI: $10.3892 /$ etm.2020.9425

'You will never walk alone'

Liverpool FC football team's anthem

\begin{abstract}
Epilepsy in childhood is one of the most common neurological disorders encountered in paediatric clinical practice. The current treatment of paediatric epilepsy aims to improve health outcomes, as well as to manage the educational, social and psychological issues that are involved in the quality of life of paediatric patients and their parents. In this direction, in several countries, a specialized, comprehensive, multidisciplinary service has been developed, including paediatric epilepsy nursing, which constitute a key component of this service. According to Mrs. Jennifer O'Brien, one of the pioneering paediatric epilepsy nursing specialists in the UK with a significant contribution in the care of children with epilepsy in Merseyside, the mission of paediatric epilepsy nursing is to enable children with epilepsy and their families to live as normal a life as possible, to ensure that all those who care for the child are well-educated regarding the child's epilepsy and to promote the child's safety and integration into society. She notes that in the past, epilepsy was not considered as a specialty and was looked after by all paediatricians; it is recognised now that it is an incredibly complex group of conditions, which deserves to have specialist management.
\end{abstract}

Correspondence to: Professor Demetrios A. Spandidos, Laboratory of Clinical Virology, Medical School, University of Crete, 71003 Heraklion, Greece

E-mail: spandidos@spandidos.gr

Dr Ioannis N. Mammas, Paediatric Clinic, Aliveri, 34500 Island of Euboea, Greece

E-mail: mammasjo@googlemail.com

Key words: paediatric epilepsy nursing, paediatric neurology, epilepsy, nurse, subspecialisation, Wirral, UK
She believes that although modern technology is crucial in informing and educating families, face to face education and advice is still the most important method of providing support. She highlights the recent advances in genetics of paediatric neurology along with the drive for epilepsy specialists, both nursing and medical, while she estimates that over the following years, paediatric epilepsy nursing will have progressed beyond nowadays expectations.

\section{Contents}

1. Introduction

2. Questions and Answers

\section{Introduction}

Since early antiquity, epileptic attacks have been described in several texts, while Hippocrates was the first who rejected the superstitious beliefs that had been related to the aetiology of epilepsy (1). Children account for $25 \%$ of all new cases of epilepsy, which occurs in both adults and children. Epilepsy in children is one of the most common neurological disorders encountered in paediatric clinical practice. It is related to learning, behavioural and psychological difficulties, while long term follow-up studies have demonstrated that children with epilepsy have an increased mortality rate when compared with the general population (2). The selection of anti-epileptic medication $(3,4)$ is performed by the paediatric neurology specialist, based on the diagnosis, the efficacy and effectiveness of different anti-epileptic drugs (AEDs) and the principle to prescribe the fewest types of AEDs, at the lowest dose in order to achieve the optimal seizure control possible with the fewest side-effects. Furthermore, the current treatment of epilepsy in children includes a number of nursing and other interventions 
aiming to improve health outcomes, as well as to manage the educational, social and psychological issues that are involved in the quality of life of paediatric patients and their parents. In this direction, in several countries, a specialized, comprehensive, multidisciplinary service has been developed aiming to the state-of-the-art medical care of children with epilepsy.

Paediatric epilepsy nursing constitutes a key component of this service, and includes care planning, facilitating appropriate participation, risk assessment, school and respite care liaison, rescue medication training and telephone advice (5-9). In the UK, paediatric epilepsy nursing specialists have a significant input in the management of children with epilepsy, which is well described by the Institute for Health and Care Excellence (NICE) clinical guidelines for epilepsy (5). Their role is to support both epilepsy specialists and generalists, to ensure access to community and multi-agency services and to provide information, training and support to the child, families, carers and others involved in the child's education, welfare and wellbeing.

Mrs. Jennifer O'Brien (Fig. 1) is one of the pioneering paediatric epilepsy nursing specialists in the UK with a significant contribution in the care of children with epilepsy in Merseyside. She has been working as a paediatric epilepsy nursing specialist since 1998. She was born on The Wirral in 1962 and has lived in Merseyside all her life. Growing up, she developed a love for children and after leaving school, she worked voluntarily in a local school for children with disabilities. She qualified as an RGN/RSCN (Registered General Nurse/Registered Sick Children's Nurse) at 'Alder Hey' Children's Hospital (Liverpool) in 1984 and for some time worked as a staff nurse at both 'Alder Hey' Children's Hospital and 'Arrowe Park' Hospital; 'Arrowe Park' Hospital is one of the biggest and busiest acute NHS (National Health System) hospitals in the North West region in the UK, which is located in Upton, Wirral, Merseyside, and managed by the Wirral University Teaching Hospital NHS Foundation Trust. After developing an interest in epilepsy at her time working in the special school, Mrs. O'Brien set up the paediatric epilepsy nursing specialist service at 'Arrowe Park' Hospital in March 1998; over the past 22 years this has developed and now has 2 full time specialist nurses. She sees new referrals from general practitioners (GPs) and the accident and emergency (A\&E) department, ensuring that children with suspected epilepsy are seen and assessed within 2 weeks - as per the NICE guidelines (5). She also provides advice and support to children with epilepsy and their families. Jenny is happily married with 2 children and 3 grandchildren. She plans to retire in 2022 to spend more time with her grandchildren and husband.

On February 22nd, 2020, Mrs. Jennifer O'Brien participated in a teleconference with the Paediatric Virology Study Group (PVSG) on paediatric epilepsy nursing, which was organized by the newly founded Institute of Paediatric Virology (IPV).

\section{Questions and Answers}

Question: First of all, Mrs Jenny O'Brien, I feel a great gratitude that I had the chance to work with you as a Senior House Officer (SHO) in Paediatrics and Neonatology at the Wirral

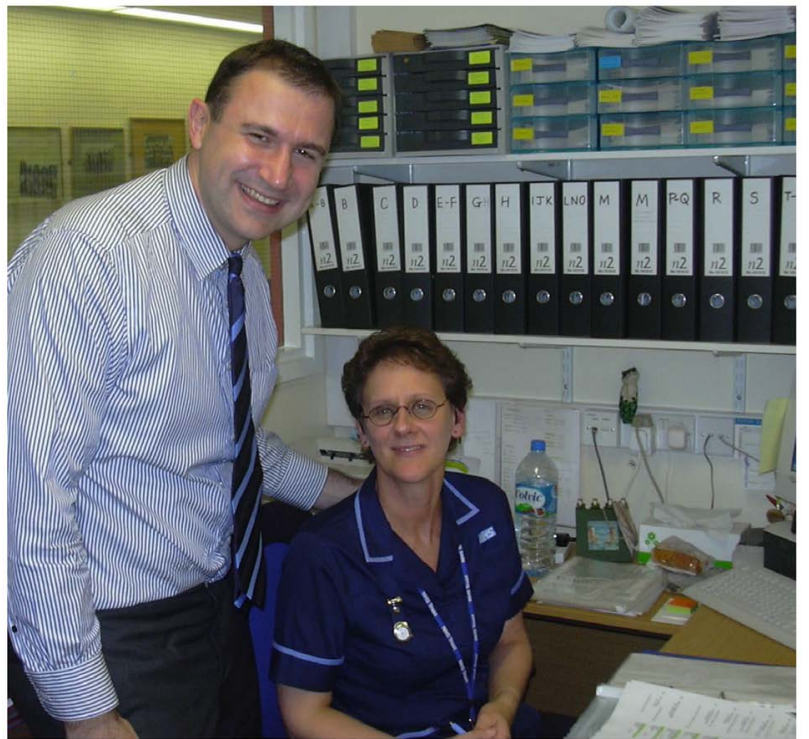

Figure 1. Dr Ioannis N. Mammas, Senior House Officer (SHO) in Paediatrics and Neonatology with Mrs. Jennifer O'Brien, paediatric epilepsy nursing specialist at the Wirral University Teaching Hospital, Wirral, UK.

University Teaching Hospital almost 12 years ago (10-12) and receive your support and your hospitality at the local Paediatric Department and the Neonatal Intensive Care Unit (NICU). The level of specialty training by all the neonatal and paediatric team directed at that time by Dr Adrian Hughes, Clinical Director and Consultant Neonatologist and Dr Lil Breen, Consultant Paediatrician was really outstanding. I would also like to thank you for this interview, which will focus on the role of paediatric epilepsy nursing specialists in the UK and will try to analyse to our Paediatric Virology Study Group (PVSG) the significant clinical, educational and research contribution of paediatric epilepsy nursing in the modern management of children with epilepsy. So, what is your mission as a paediatric epilepsy nursing specialist?

Answer: My mission is to enable children with epilepsy and their families to live as normal a life as possible. It is recognised that the psychological burden on these children and their families is significant, and having an experienced person to whom they can talk can ease some of the stress. I also aim to ensure that all those who care for the child are educated regarding the child's epilepsy, to ensure the child's safety and integration into society.

Question: Could you describe to us examples from your clinical experience that highlight your significant supportive role to the children with epilepsy and their parents? Could you give us examples that show how your input improves patient satisfaction as well as the level of the received medical care? Answer: It's difficult to choose some examples. I have developed good relationships with many of the families I have worked with. Many of them keep in touch, even though their children are now adults. I recently learned that one of my ex patients who was 21 was receiving care in adult intensive therapy unit (ITU). He was a young man with physical and learning difficulties and I had known the family well. I was able to visit him and his family in the ITU. Sadly, he died a week later, but the family contacted me with the details of his 
funeral. Even following the death of a patient, we can continue to support the family.

I have a treasured gift from a family whose 2 children I cared for. They both had learning disabilities and difficult epilepsy. I cared for the siblings for 18 years and when they were handed on to the adult clinic they gave me a framed plaque. This plaque is really so nice showing how much my input means to the family.

Just 2 weeks ago, a child was referred to my nurse led clinic following a first seizure. She had been seen at the A\&E after the seizure and discharged. When I saw her, in addition to the history of one nocturnal seizure, her parents told me that she had become increasingly unsteady, had experienced several episodes of nocturnal vomiting and complained of a frequent headache. I was concerned about the history and an urgent magnetic resonance imaging (MRI) was arranged, which showed a large tumour pressing on the brain stem. She was transferred to 'Alder Hey' Children's Hospital for surgery and seems to have made an excellent recovery so far. Although she didn't have a diagnosis of epilepsy, having only had one seizure, I feel that I provided excellent care to the family.

Question: One of your responsibilities as a paediatric epilepsy nursing specialist is to inform and educate children with epilepsy and their parents. How demanding is this for you? What educational tools do you use and how does modern technology facilitate your practice?

Answer: Modern technology is crucial in informing and educating families. In the past, we would provide written information, but increasingly we are using the internet to access advice and support. There are a number of applications available from the epilepsy charities which can support young people to remember medication for example. However, face to face education and advice is still the most important way of providing support. Education is provided either on a one to one basis or in a group setting. We have recently started to hold epilepsy tea parties. We invite newly diagnosed children and their families to meet each other, have some fun and learn something about epilepsy in to the bargain. This is a low-tech way to improve their lives and has proved to be very successful.

Questions: Viral infections causing encephalitis are often associated with seizures and can increase the risk of developing children's epilepsy. Moreover, viral infections can frequently trigger a convulsion's episode in a child with epilepsy. What advice do you give in children with epilepsy who are affected by a viral infection?

Answer: We advise all families, whose children are affected by a viral infection, to keep the child comfortable with analgesia/ antipyretics. To ensure they are hydrated, to encourage rest. If a child vomits within $1 \mathrm{~h}$ of taking their anti epileptic medication, we advise giving the dose again. If the child is not tolerating fluids, and has diarrhoea, we suggest that they contact the hospital for advice.

Question: On the other hand, febrile convulsions are frequently presented in children with pyrexia due to a viral infection. At the Wirral University Teaching Hospital a febrile convulsion pathway has been developed according to which no admission is required in cases of children with febrile non-complicated convulsions (11). Based on your clinical practice, what should be the management of children with febrile convulsions?

Answer: As long as the seizure was relatively short, accompanied by significant pyrexia and has no focal features the child should be discharged home when it is safe to do so. Parents should be given advice about managing fever and any further seizures. We do not advise that children with febrile seizures are routinely followed up in outpatients. However, if a child has a history of multiple or complicated febrile seizures, we suggest they are referred to epilepsy clinic for assessment.

Question: How many cases do you evaluate every day or every week at your outpatient clinic? In what cases do you perform a referral? How important is team working in your practice?

Answer: I do a nurse led first seizures clinic each week. In this clinic I see referrals from GPs and A\&E assessment ward. I see approximately 5 children each week in this clinic. Many of them will be referred back to the GP with other diagnoses. Approximately 1-2 per week will be referred for further investigations for possible epilepsy - e.g., electroencephalogram (EEG), MRI. Team working is crucial. The epilepsy team now consists of 2 consultants and 2 specialist nurses. The work is allocated to the most appropriate member of the team. Advice is shared between all members of the team. In the past month we have appointed a clinical psychologist to work in the paediatric department. She will cover all specialties but we are hoping she will be able to provide support for those of our children who have psychological difficulties (including anxiety, depression and psychogenic non epileptic seizures).

Question: As a paediatric epilepsy nursing specialist you spend time both at the hospital as well as the community. What are the different challenges in each environment? Which one do you enjoy most?

Answer: As my role has evolved, I spend less time in the community. At one time I used to visit new referrals at home and take a history to save a visit to the hospital. This was done at a convenient time for the family (usually after school). I would also do a follow-up visit after diagnosis for education and support purposes. Now, new referrals are allocated to my hospital clinic. The time spent in the community is now limited to school/nursery visits for training or meetings. I have a specialist nurse colleague, who has been working with me for the past 16 months. She has taken on many home visits, to newly diagnosed children. She is able to provide support and education in the more relaxed environment of the child's home.

Question: The treatment of epilepsy is definitely more than prescribing anti-epileptic medication (6). Have you obtained, though, the prescribing right? What were the reasons for the initial hesitance of the acceptance of this right into your practice?

Answer: I have now been a nurse prescriber for 10 years. I don't remember my reasons for being hesitant, unless it was a lack of confidence on my part. I have found it invaluable being able to prescribe. It allows me to care for the child as a whole, including initiating treatment and altering drug doses. I am also able to advise other members of the team, both nursing and medical on the best options for treatment. 
Question: What happens when children with epilepsy or their parents disagree to receive the recommended treatment? What are the most common reasons for this and how do you manage these cases?

Answer: It is rare that parents disagree with our recommendations. However, some do not feel comfortable with their child receiving a drug with potential side-effects. If the child has infrequent, short seizures we will often agree to keep monitoring the child in the clinic. If the seizure frequency increases or the seizures become more risky, we would then encourage the families to consider medication. We often find that with patience we can reassure them. Many of them have unfounded fears about the effects of anti-epileptics. We reassure them that if the medication is not tolerated, we would try an alternative drug. Interestingly, it is more common for parents to want to keep their child on treatment longer than is necessary. This is due to anxiety that the child will have further seizures. We try to manage this sensitively, while explaining that childhood is the best time to have a trial off medication. Once the child is at university/driving/working, it becomes more difficult to find a good time to withdraw the medication and there is a risk that they end up taking it potentially for life.

Question: It is really so important to help children with epilepsy and their parents and maximize their quality of life, indeed. How could you define the quality of life in your little patients? Answer: Quality of life is highly subjective. In my work I see a range of children all with different values, goals and abilities. Seizure freedom is not always possible, so we try to ensure that children are as seizure-free as possible, without causing intolerable side-effects from medications. It is better to have occasional seizures and to be well in between times, than to be seizure-free but so tired that you can't enjoy your life. Having the freedom to do as their friends do without unnecessary restrictions is also important. We try to ensure this by educating parents/carers and teachers.

Question: Your educational role is significant not only for children with epilepsy and their parents, but for your paediatric colleagues, too; to date, this role has been evaluated very positively. What are the most significant educational fields of your input to the paediatric specialty training (ST) programme? Answer: I don't provide a great deal of training for the paediatric trainees. I am part of the training rota and provide sessions several times a year. These sessions provide basic information about how we manage epilepsy and when to refer children to our service. I teach the ward nurses on a regular basis to ensure that they are up to date with current ideas.

Question: You are also very actively involved in clinical research. Could you analyse to us some of the results of your clinical research and your audits during the last years?

Answer: As an epilepsy team, we have been involved with several audits. We were significant contributors to both Standard and New Antiepileptic Drugs (SANAD) I (3) and SANAD II (4), United Kingdom Infantile Spasms Study (UKISS) (13) and the International Collaborative Infantile Spasms Study (ICISS) (14). We are contributing on an ongoing basis to the Epilepsy12 audit (15). This is a national rolling audit, which has 12 standards of good practice. All newly diagnosed children are added to the audit. The most recent study we are involved in is the CASTLE (Changing Agendas on Sleep, Treatment and Learning in Childhood Epilepsy) study (16).

Question: What training did you receive in order to be subspecialised in paediatric epilepsy nursing? Is there an official training programme in the UK that could be currently attended by a nurse who is interested in children's epilepsy?

Answer: Twenty two years ago when I applied for this role I only had my basic paediatric nurse qualification. After starting in post I undertook a distance learning diploma in epilepsy care. Since then I have attended paediatric epilepsy training (PET) 1,2 and 3 training days. I have also undertaken my independent non-medical prescribing training.

Question: Based on your experience, what are the most significant advances in your field during the last decade? What issues remain to be solved by future research in your field?

Answer: I would say that advances in our understanding of genetics have been the most significant, along with the drive for epilepsy specialists, both nursing and medical. In the past, epilepsy was not considered as a specialty and was looked after by all paediatricians. It is recognised now that it is an incredibly complicated group of conditions which deserves to have specialist management. We are still at the beginning of our understanding of the way genetics influences epilepsy - we have a long way to go. I think over the next 20 years we will have progressed beyond our expectations.

Question: And my last question. You are considered as one of the most successful and well-known paediatric epilepsy nursing specialists in the UK. Should the role of paediatric epilepsy nursing specialists be further promoted in the UK and how? What is your advice to your paediatric colleagues in countries where your specialty has not been developed yet? Answer: Although I am now one of the longest serving children's epilepsy nurses, I don't feel I am particularly well known. Many regions in the UK now have paediatric epilepsy nurses. Parent power is the most powerful ways to persuade local health authorities to provide funding for specialist nurses. Most paediatricians recognise their value, but the funding is often difficult to secure. NICE guidelines recommend that all children with epilepsy have a specialist nurse (5). The Epilepsy12 audit (15) may well be a useful tool to help those units who are struggling to obtain funding.

Question: Thank you for your very interesting answers. We hope that this interview will be really useful for junior paediatric trainees as well as for your paediatric nursing colleagues especially in countries where paediatric epilepsy nursing has not been developed yet. Although subspecialisation in medicine can create more problems than it tries to solve, paediatric epilepsy nursing is a good paradigm of how significant it can be into paediatric clinical practice. And without any doubt your pioneering contribution on paediatric neurology nursing is an excellent model for our international paediatric medical and nursing community. We look forward to your participation in one of the forthcoming workshops organised by the IPV. 


\section{Acknowledgements}

This article is published in the context of the foundation of the Institute of Paediatric Virology (IPV; https:// paediatricvirology.org) based on the island of Euboea (Greece), under the auspices of the World Academy of Sciences (WAS) and the support of the Department of Clinical Virology of the University of Crete School of Medicine and the First Department of Paediatrics of the University of Athens School of Medicine. We would like to thank all the members of the IPV for their valuable comments and corrections.

\section{Funding}

No funding was received.

\section{Availability of data and materials}

Not applicable.

\section{Authors' contributions}

INM and DAS contributed equally to the conception and design of this manuscript, wrote the original draft, edited and critically revised the manuscript, read and approved the final manuscript.

\section{Ethics approval and consent to participate}

Not applicable.

\section{Patient consent for publication}

Not applicable.

\section{Competing interests}

INM and DAS are Co-founders of the Institute of Paediatric Virology (IPV). DAS is the Editor-in-Chief for the journal, but had no personal involvement in the reviewing process, or any influence in terms of adjudicating on the final decision, for this article.

\section{References}

1. Hippocrates: On the Sacred Disease. In: Hippocrates Apanta 16. Kaktos Editions, Athens, 1993 (In Greek).

2. Appleton R: Mortality in paediatric epilepsy. Arch Dis Child 88: 1091-1094, 2003.
3. Marson AG, Al-Kharusi AM, Alwaidh M, Appleton R, Baker GA, Chadwick DW, Cramp C, Cockerell OC, Cooper PN, Doughty J, et al: The SANAD study of effectiveness of valproate, lamotrigine, or topiramate for generalised and unclassifiable epilepsy: an unblinded randomised controlled trial. Lancet 369: 1016-1026, 2007.

4. Marson AG, Burnside G, Appleton R, Leach J, Sills G, Tudor C, Hughes D, Williamson P, Baker G, Hickey H, et al: The SANAD II study of effectiveness of valproate or levetiracetam in generalised and unclassifiable epilepsy: an un-blinded randomised controlled trial. Epilepsia 60 (Suppl 2): P642, 2019.

5. The National Institute for Health and Care Excellence (NICE): Epilepsy in children and young people. Quality standard [QS27]. NICE, 2013. https://www.nice.org.uk/guidance/qs27. Accessed February 28, 2013.

6. Appleton RE and Sweeney A: The management of epilepsy in children: The role of the clinical nurse specialist. Seizure 4: 287-291, 1995.

7. Epilepsy action: ESPENTE (Epilepsy Specialist Nurses - The Evidence). Epilepsy Action, Leeds, 2010. https://www.epilepsy. org.uk/research/espente.

8. Hargreaves DS, Arora S, Viveiro C, Hale DR, Ward JL, SherlawJohnson C, Viner RM, Dunkley C and Cross JH: Association of quality of paediatric epilepsy care with mortality and unplanned hospital admissions among children and young people with epilepsy in England: A national longitudinal data linkage study. Lancet Child Adolesc Health 9: 627-635, 2019.

9. Royal College of Nursing: Specialist nursing of children and young people with epilepsy. https://www.epilepsy.org.uk/sites/ epilepsy/files/professionals/competency_frameworks/Paediatric_ epilepsy_specialist_nurse_competencies.pdf. Updated December 2013.

10. Stewart J, Mammas I and Hughes A: An educational DVD on children's epilepsy. Wirral University Teaching Hospital, 2007.

11. Mammas I, Breen L and Hughes A: Management of children with febrile convulsions: A pathway-based approach. J Paediatr Child Health 45: 236-237, 2009.

12. Shaheena K, Stewart J, Mammas IN and Hughes A: An audit of the appropriateness and outcomes of 12 months of EEG referrals from a district general paediatric department. Arch Dis Child 93: A57-A58, 2008

13. Lux AL, Edwards SW, Hancock E, Johnson AL, Kennedy CR, Newton RW, O'Callaghan FJ, Verity CM and Osborne JP; United Kingdom Infantile Spasms Study: The United Kingdom Infantile Spasms Study (UKISS) comparing hormone treatment with vigabatrin on developmental and epilepsy outcomes to age 14 Months: A multicentre randomised trial. Lancet Neurol 4: 712-717, 2005.

14. O'Callaghan FJK, Edwards SW, Alber FD, Cortina Borja M, Hancock E, Johnson AL, Kennedy CR, Likeman M, Lux AL, Mackay MT, et al: Vigabatrin with hormonal treatment versus hormonal treatment alone (ICISS) for infantile spasms: 18-month outcomes of an open-label, randomised controlled trial. Lancet Child Adolesc Health 2: 715-725, 2018.

15. Royal College of Paediatrics and Child Health ( $\mathrm{RCPCH})$ : Epilepsy12 audit. RCPCH, 2020. https://www.rcpch.ac.uk/workwe-do/quality-improvement-patient-safety/epilepsy12-audit.

16. King's College London: The CASTLE study, 2020. http://castlestudy.org.uk/.

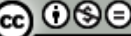

This work is licensed under a Creative Commons Attribution-NonCommercial-NoDerivatives 4.0 International (CC BY-NC-ND 4.0) License. 